\title{
Prevalence and Correlates of Psychiatric Symptoms in North Korean Defectors
}

\author{
Hyo Hyun Kim¹, Yu Jin Lee ${ }^{2,4} \bowtie$, Ha Kyoung Kim³, Jung Eun Kim², \\ Seog Ju Kim², Seung-Min Bae ${ }^{2}$ and Seong-Jin $\mathrm{Cho}^{2}$ \\ ${ }^{1}$ Gachon University of Medicine and Science, ${ }^{2}$ Department of Psychiatry, Gachon University of Medicine and Science, Incheon, Korea \\ ${ }^{3}$ Department of Mental Health, Seoul National Hospital, Seoul, Korea \\ ${ }^{4}$ Incheon Metropolitan Mental Health Center, Incheon, Korea
}

Objective The aim of the present study is to assess the prevalence of psychiatric symptoms and associated factors in North Korean Defectors (NKDs).

Methods One hundred forty-four NKDs (male: 20; female: 124; average age: $40.4 \pm 11.7$ yrs.) completed the Symptom Checklist-90Revised (SCL-90-R) and the Center for Epidemiologic Studies Depression scale (CES-D). A stepwise logistic regression analysis was conducted to evaluate factors associated with the psychiatric symptoms of the participants.

Results NKDs mainly reported somatization (42.4\%) and depressive symptoms (38.9\%). Female NKDs showed higher prevalence of somatization $(\mathrm{p}=0.001)$, anxiety $(\mathrm{p}=0.020)$, hostility $(\mathrm{p}=0.026)$ and psychoticism $(\mathrm{p}=0.022)$ than males. The presence of physical illness was strongly related to most psychiatric symptoms on the SCL-90-R including somatization ( $<<0.001)$, obsessive-compulsive symptoms $(p=0.020)$, interpersonal sensitivity $(p=0.031)$, depression $(p<0.001)$, anxiety $(p<0.001)$, hostility $(p=0.011)$, paranoid ideation $(p=0.015)$ and psychoticism $(\mathrm{p}<0.001)$. Younger age, unemployment, lower income, and longer duration of defection were found to be the risk factors of psychiatric symptoms. In regard to mental health service utilization, we found that most (83.3\%) of the participants had not received any form of psychiatric help.

Conclusion Somatization and depression were the most prevalent psychiatric symptoms in NKDs. Our results suggest that psychiatric symptoms accompany certain sociodemographic and clinical characteristics that are associated with susceptibility to acculturation stressors. An understanding of these factors will be helpful providing appropriate mental health services to NKDs.

Psychiatry Investig 2011;8:179-185

Key Words North Korean defectors, Psychiatric symptoms, Acculturation.

\section{INTRODUCTION}

The number of defecting North Koreans has increased considerably since 1995, and by 2009 more than 15,000 defectors had entered South Korea. ${ }^{1}$ With the ever-increasing number of North Korean Defectors (NKDs) entering South Korea, helping their successful adaptation to South Korean society has become a major undertaking for the government of South Korea. ${ }^{2}$ The mental health of refugees or immigrants has been re-

Received: December 31, 2010 Revised: March 3, 2011

Accepted: March 11, 2011 Available online: July 19, 2011

$\triangle$ Correspondence: Yu Jin Lee, MD, PhD

Department of Psychiatry, Gachon University of Medicine and Science, 1198 Guwol-dong, Namdong-gu, Incheon 405-760, Korea

Tel: +82-32-468-9932, Fax: +82-32-472-3396, E-mail: ewpsyche@hanmail.net

(a) This is an Open Access article distributed under the terms of the Creative Commons Attribution Non-Commercial License (http://creativecommons.org/licenses/bync/3.0) which permits unrestricted non-commercial use, distribution, and reproduction in any medium, provided the original work is properly cited. ported to have a significant effect on their ability to adapt and settle in their new environment, i.e., acculturate., ${ }^{3,4}$

Prior studies reported that the decisive factors for the mental health of refugees were psychological traumas experienced during their escaping periods, i.e., the period of time between escaping from the country of origin and finally arriving in the country where the defector settles. ${ }^{5-7}$ On the other hand, some studies have noted that risk and resilience factors in the postmigratory environment have an even stronger relationship with psychological morbidity than exposure to traumatic events. ${ }^{8-10}$

A number of studies on the mental health of refugees have focused on symptoms of post-traumatic stress disorder (PTSD), depression and anxiety. ${ }^{11-15}$ According to the previous studies on the mental health of NKDs in South Korea, $37.6 \%$ of defectors experienced psychological problems; $22.2 \%$ suffered from depression, $18.8 \%$ complained anxiety, and $18.2 \%$ had 
PTSD. $^{13}$

However, few study has assessed overall psychiatric symptoms and their correlates among NKDs.

We conducted the present study with three objectives. Firstly, we assessed prevalence of overall psychiatric symptoms among NKDs rather than concentrating on PTSD symptoms. Secondly, we explored contributory risk factors to explain psychiatric symptoms in NKDs. Thirdly, we investigated the utilization of mental health services by NKDs.

\section{METHODS}

The participants were 144 NKDs aged 21 to 75 years living in the city of Incheon in Republic of Korea between July and October, 2009 (20 males, 124 females; mean age 40.4 \pm 11.7 years). They completed the Symptom Checklist-90-Revised (SCL-90-R) and the Center for epidemiologic studies depression scale (CES-D), after informed consents for all participants were obtained. In addition, brief questionnaire on sociodemograpic characteristics, physical illnesses, subjective general health status and mental health service utilization was also completed.

\section{Symptom Checklist-90-Revised (SCL-90-R)}

The SCL-90-R is a 90 item self-report inventory developed in the 1980s by Derogatis for the assessment of broad range of psychological problems and symptoms of psychopathology. ${ }^{16}$ It has been used as a screening measure of general psychiatric symptomatology. The SCL-90-R is a revised version of the original SCL-90. The SCL-90-R replaces some of the items on the Anxiety and the Obsessive-Compulsive dimensions of the SCL-90 that were flawed psychometrically. Each of the 90 items is rated on a five-point scale of distress (from " $0=$ not at all" to " $4=$ extremely"). Patients are asked to rate the severity of their experiences with each symptom over the past week. Responses are scored in terms of nine primary psychiatric symptom dimensions: somatization, obsessive-compulsive symptoms, interpersonal sensitivity, anger-hostility, depression, anxiety, paranoid ideation, phobic anxiety and psychoticism. ${ }^{16-18}$ Participants with $\mathrm{T}$ score on each dimension higher than 60 were considered to have an appreciable level of symptoms. ${ }^{16}$

\section{Center for Epidemiologic Studies Depression Scale (CES-D)}

The CES-D is a 20 item self-report questionnaire, which assesses the extent of depressive symptoms experienced during the past week. ${ }^{19}$ Items are scored on a four-point scale from 0 (rarely) to 3 (most or all of the time) so that higher scores reflect more severe depressive symptoms. In the present study, participants completed the Korean version of the CES-D, which has been found to have high reliability and validity. ${ }^{20}$ In the current study, score of 21 was used for cut-off of being significant depressive mood. ${ }^{20}$

\section{Mental Health Services Utilization}

The utilization of mental health care services since having defected from North Korea was assessed by recording the participants' responses to the following questions: 1) "Have you ever felt a need for mental health services during last year?", 2) "Have you ever used mental health services?", 3) "If you have, what kind of the facility was?", 4) "If you haven't, what was the reason?".

Descriptive statistics were used to summarize sociodemographic characteristics. The primary symptom dimensions of participants were analyzed according to gender by chi-square tests. A stepwise logistic regression analysis was performed to explore the relationships between the nine primary psychiatric symptom dimensions and the sociodemographic characteristics.

All calculations were performed using Statistical Package for Social Sciences (SPSS version 15.0; SPSS Inc., Chicago, IL, USA), and a p-value $<0.05$ was considered to indicate statistical significance in all analyses.

\section{RESULTS}

\section{Characteristics of the study population}

A summary of the sociodemographic characteristics of the participants is shown in Table 1. Most (72.9\%) were married, however, just over a half of the participants (54.9\%) escaped from North Korea along with their family. Ninety-eight subjects $(68.1 \%)$ had an escaping period in a third country of more than three years, and the mean escaping period in a third country was $66.3 \pm 48.0$ months. One hundred twenty four subjects $(86.1 \%)$ have stayed for more than one year in South Ko-

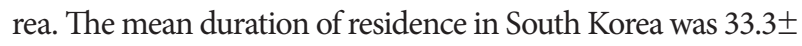
24.9 months

The majority of the subjects $(88.9 \%)$ were unemployed at the time of the study, and 85 subjects (59.0\%) had no monthly income. The defectors received an average of $10.1 \pm 2.8$ years of education in North Korea, and 99 (69.2\%) graduated from high school in North Korea, and only 5 had received further education in a South Korean college or university.

Seventy-seven of the defectors (54.2\%) had physical illnesses or symptoms (Table 1).

\section{Prevalence of psychiatric symptoms}

Table 2 presents the prevalence of psychiatric symptoms on each of the nine SCL-90-R dimensions. Participants with T score on each dimension higher than 60 were considered to 
Table 1. Sociodemographic characteristics of subjects $(\mathrm{N}=144)$

\begin{tabular}{|c|c|c|}
\hline \multicolumn{2}{|l|}{ Variable } & \multirow{2}{*}{$\frac{n(\%)}{20(13.9)}$} \\
\hline Gender & Male & \\
\hline & Female & $124(86.1)$ \\
\hline \multirow[t]{6}{*}{ Age (yr) } & $20-29$ & $20(13.9)$ \\
\hline & $30-39$ & $60(41.7)$ \\
\hline & $40-49$ & $40(27.8)$ \\
\hline & $50-59$ & $11(7.6)$ \\
\hline & $60-69$ & $6(4.2)$ \\
\hline & 70 and above & $7(4.9)$ \\
\hline \multirow[t]{4}{*}{ Marital status } & Married & $105(72.9)$ \\
\hline & Single & $25(17.3)$ \\
\hline & Separated/Widowed/Divorced & $9(6.3)$ \\
\hline & Missing data & $5(3.5)$ \\
\hline \multirow[t]{2}{*}{ Escaping with family } & Yes & $79(54.9)$ \\
\hline & No & $65(45.1)$ \\
\hline \multicolumn{2}{|c|}{ Escaping period in a third country (month) } & $66.3 \pm 48.0$ \\
\hline \multicolumn{2}{|c|}{ Residence period in South Korea (month) } & $33.3 \pm 24.9$ \\
\hline \multirow[t]{2}{*}{ Employment } & Employed & $16(11.1)$ \\
\hline & Unemployed & $128(88.9)$ \\
\hline \multirow[t]{5}{*}{ Income (/month) } & $>1,500,000$ won & $5(3.5)$ \\
\hline & $500,000-1,500,000$ won & $32(22.2)$ \\
\hline & $1<$ and $<500,000$ won & $14(9.7)$ \\
\hline & No income & $85(59.0)$ \\
\hline & Missing data & $8(5.6)$ \\
\hline \multirow{4}{*}{$\begin{array}{l}\text { Educational level } \\
\text { in North Korea }\end{array}$} & No & $1(0.7)$ \\
\hline & $\sim$ Elementary school graduate & $8(5.6)$ \\
\hline & $\sim$ Middle-high school & $99(69.2)$ \\
\hline & $\sim$ College/University & $35(24.5)$ \\
\hline \multirow{3}{*}{$\begin{array}{l}\text { Presence of physical } \\
\text { illness }\end{array}$} & Yes & $77(54.2)$ \\
\hline & No & $65(45.1)$ \\
\hline & Missing data & $2(1.4)$ \\
\hline \multirow{6}{*}{$\begin{array}{l}\text { Gastrointestinal } \\
\text { diseases }(n=40)\end{array}$} & Gastritis/Gastric ulcer & $20(13.9)$ \\
\hline & Esophagitis & $5(3.5)$ \\
\hline & Liver disease & $8(5.6)$ \\
\hline & Gall stone & $1(0.7)$ \\
\hline & Pancreatitis & $1(0.7)$ \\
\hline & Unknown & $5(3.5)$ \\
\hline \multirow{4}{*}{$\begin{array}{l}\text { Cardiovascular } \\
\text { diseases }(n=10)\end{array}$} & Hypertension & $6(4.2)$ \\
\hline & Hypotension & $3(2.1)$ \\
\hline & Hyperlipidemia & $1(0.7)$ \\
\hline & Unknown & $2(1.4)$ \\
\hline \multirow{3}{*}{$\begin{array}{l}\text { Musculoskeletal } \\
\text { diseases }(n=9)\end{array}$} & Back pain/Hernia of disk & $7(4.9)$ \\
\hline & Knee joint disease & $1(0.7)$ \\
\hline & Unknown & $1(0.7)$ \\
\hline
\end{tabular}

Table 1. Continued

\begin{tabular}{lll}
\hline Variable & & $\mathrm{n}(\%)$ \\
\hline Endocrine/ & Diabetes mellitus & $3(2.1)$ \\
Infectious & Thyroid gland disease & $1(0.7)$ \\
diseases $(\mathrm{n}=5)$ & TB pleurisy & $1(0.7)$ \\
Nervous system & Headache & $2(1.4)$ \\
diseases $(\mathrm{n}=4)$ & Dizziness & $1(0.7)$ \\
& Brain tumor & $1(0.7)$ \\
Urinary diseases & Kidney stone & $2(1.4)$ \\
$(\mathrm{n}=4)$ & Urinary track infection & $1(0.7)$ \\
& Unknown & $1(0.7)$ \\
Pulmonary diseases & Bronchitis & $1(0.7)$ \\
$(\mathrm{n}=2)$ & Unknown & $1(0.7)$ \\
\hline
\end{tabular}

have an appreciable level of symptoms. ${ }^{16}$ The NKDs reported predominantly somatization (42.4\%) and depressive symptoms (38.9\%). Females reported a higher prevalence of somatization $\left(X^{2}=9.962, \mathrm{p}=0.001\right)$, anxiety $\left(X^{2}=5.973, \mathrm{p}=0.020\right)$, hostility $\left(\chi^{2}=4.955, \mathrm{p}=0.026\right)$ and psychoticism $\left(\chi^{2}=5.237, \mathrm{p}=0.022\right)$ than males.

Among NKDs, depressive symptoms (CES-D scores of 21 or more) were found in $52.4 \%$ of the female and $30.0 \%$ of the male (mean score on CES-D in current study was $23.5 \pm 13.7$ ).

\section{Contributory factors associated with psychiatric symptoms}

The results of the stepwise logistic regression analysis are summarized in Table 3. The presence of physical illness was associated with the significant level of symptoms on the nine primary psychiatric symptom dimensions, including somatization ( $\beta=-1.895, p<0.001)$, obsessive-compulsive $(\beta=-1.061$, $\mathrm{p}=0.020)$, interpersonal sensitivity $(\beta=-0.980, \mathrm{p}=0.031)$, depression $(\beta=-1.515, p<0.001)$, anxiety $(\beta=-1.804, p<0.001)$, hostility $(\beta=-1.243, p=0.011)$, paranoid $(\beta=-1.098, p=0.015)$ and psychoticism $(\beta=-1.842, \mathrm{p}<0.001)$.

Our results also showed that female gender was associated with more prevalent somatization $(\beta=2.483, p=0.005)$, and younger age was associated with hostility $(\beta=-0.053, p=0.039)$ and paranoid ideation $(\beta=-0.050 ; p=0.033)$. Unemployment was related to higher prevalence of obsessive-compulsive symptoms $(\beta=2.769, \mathrm{p}=0.022)$ and psychoticism $(\beta=2.013$, $\mathrm{p}=$ $0.037)$. Low monthly income was related to obsessive-compulsive symptoms $(\beta=-0.431, \mathrm{p}=0.046)$ and interpersonal sensitivity ( $\beta=-0.552, p=0.012$ ). The longer the duration of the escaping period, the more likely the participants were to report depressive symptoms on SCL-90- $\mathrm{R}(\beta=0.102, \mathrm{p}=0.044)$.

\section{The status for mental health services utilization}

Table 4 summarizes the responses to the questions about uti- 
Table 2. Prevalence of psychiatric symptoms measured by SCL-90-R or CES-D ( $N=144)$

\begin{tabular}{|c|c|c|c|c|c|c|c|c|}
\hline \multirow{2}{*}{ Dimension } & \multicolumn{2}{|c|}{ Male $(\mathrm{N}=20)$} & \multicolumn{2}{|c|}{ Female $(\mathrm{N}=124)$} & \multicolumn{2}{|c|}{$\operatorname{Total}(\mathrm{N}=144)$} & \multirow{2}{*}{$\chi^{2}$} & \multirow{2}{*}{ p-value } \\
\hline & $\mathrm{N}$ & $\%$ & $\mathrm{~N}$ & $\%$ & $\mathrm{~N}$ & $\%$ & & \\
\hline Somatization $(\mathrm{SOM})^{* *}$ & 2 & 10.0 & 59 & 47.6 & 61 & 42.4 & 9.962 & 0.001 \\
\hline Obsessive-Compulsive (O-C) & 3 & 15.0 & 36 & 29.0 & 39 & 27.1 & 1.717 & 0.279 \\
\hline Interpersonal Sensitivity (I-S) & 3 & 15.0 & 35 & 28.2 & 38 & 26.4 & 1.551 & 0.280 \\
\hline Depression (DEP) & 5 & 25.0 & 51 & 41.1 & 56 & 38.9 & 1.885 & 0.170 \\
\hline Anxiety (ANX)* & 2 & 10.0 & 47 & 37.9 & 49 & 34.0 & 5.973 & 0.020 \\
\hline Hostility (HOS)* & 1 & 5.0 & 35 & 28.2 & 36 & 25.0 & 4.955 & 0.026 \\
\hline Phobic Anxiety (PHOB) & 2 & 10.0 & 39 & 32.0 & 41 & 28.9 & 4.038 & 0.061 \\
\hline Paranoid Ideation (PAR) & 5 & 25.0 & 34 & 27.4 & 39 & 27.1 & 0.051 & 0.821 \\
\hline Psychoticism (PSY)* & 2 & 10.0 & 44 & 35.8 & 46 & 32.2 & 5.237 & 0.022 \\
\hline Depressive symptom (CES-D $\geq 21$ ) & 6 & 30.0 & 65 & 52.4 & 71 & 49.3 & 3.463 & 0.091 \\
\hline
\end{tabular}

${ }^{*} \mathrm{p}<0.05,{ }^{* *} \mathrm{p}<0.01$. SCL-90-R: symptom Checklist-90-Revised, CES-D: Center for Epidemiologic Studies-Depression Scale

lization of mental health services. Among 144 subjects, ninety-three (64.6\%) of the subjects reported that they thought subjectively their own general health status was poor. Sixty-nine subjects $(47.9 \%)$ had felt need for taking mental health services during past year. However, 120 participants (83.3\%) said they had not received any form of psychiatric help. The most commonly reported barrier in accessing mental health services was insufficient information (56.3\%).

\section{DISCUSSION}

To the best of our knowledge, the present study is the first study to explore a comprehensive range of psychiatric symptoms experienced by NKDs using the SCL-90-R. Our results indicated that the most common psychiatric symptoms were somatization and depression in NKDs and they were related to physical illness and several sociodemographic variables such as younger age, female, socioeconomic status and duration of the escaping period.

Somatization has been widely reported among refugees. ${ }^{21}$ Psychological theorists have viewed somatization as an alternative to depression. ${ }^{21,22}$ Other investigations have demonstrated the association between PTSD and somatization. ${ }^{23,24}$ According to these studies, PTSD symptoms, particularly psychological numbing, was the best predictor of somatization after controlling for mood and anxiety disorders. ${ }^{24}$ Many studies have shown that refugees and immigrants from Asia are especially were predisposed to somatization during the acculturation process. ${ }^{22,25}$ This may be attributed to their traditional culture which tend to discourage the direct expression of emotional distress. Although there are limited number of researches on cultural adjustment experiences of NKDs, NKDs share Asian cultural backgrounds and may have difficulty in dealing with emotional distress when they confront with accultur- ation stressors. In addition, NKDs have reportedly had high rate of PTSD. ${ }^{2}$ It may explain high rate of somatization in our participants.

The prevalence of depressive symptoms found in the present study was twice as high as that found in the South Korean general population using the CES-D scale. ${ }^{26}$ This result is consistent with notions in previous studies on NKDs. ${ }^{27-29}$

Physical symptoms were reported to be an important antecedent of depressive symptoms. ${ }^{30,31}$ A prior study on the patients treated in public mental health facilities reported that $45 \%$ of the patients had an active physical disease and one sixth had a disease causing or exacerbating his or her mental disorder. ${ }^{32}$ And somatic symptoms and disorders were linearly correlated with depressive symptoms in a study on immigrants in a western country. ${ }^{33}$ The present findings therefore add to prior knowledge that physical health problem is a risk factor for psychiatric symptoms in refugees or immigrants. .

Our results indicated that younger subjects more likely present with hostility and paranoid ideation symptoms. Youths have developmental tasks such as establishing identity and independence and these tasks pose particular challenges when they are adapting to a new society. ${ }^{34}$ Young NKDs might have high expectations of what their life would be like when they moved to South Korea and experiencing disappointment might make them hostile and suspicious when they realize that their expectations are inaccurate.

In current study, compared with males, females reported more somatization, anxiety, hostility and psychoticism, but there were no gender differences in depressive symptoms on either the SCL-90-R or the CES-D. This result supports the finding in a previous study, which also reported no significant gender differences in depressive symptoms in NKDs. ${ }^{27}$

Financial difficulties have been associated with a higher risk of mental disorders among refugees. ${ }^{35}$ Employment is known 
to be associated with a lower risk of mental disorders and to be helpful for the recovery from mental disorders. ${ }^{36,37}$ In accordance with previous studies, our findings suggested significant relationships between unemployment, lower income and psychiatric symptoms among NKDs.

The relationship between psychiatric symptoms and the escaping period in a third country showed the expected results in terms of depressive symptom. A number of studies have addressed escaping period as a risk factor for psychopathology. ${ }^{38-41}$ Previous findings indicated that the mental health of NKDs got worse after a prolonged escaping period, and this is consistent with our results. ${ }^{42,43}$

In this study, marital status and escaping without family were not related to any of the psychiatric symptom dimension. In previous studies on refugees, it has been reported that separation from family members could cause psychological distress and was related to the prevalence of PTSD symptom. ${ }^{39,44}$ Jeon et al. also reported traumas related to family members in NKDs were associated with the development of PTSD. ${ }^{2}$ This difference may be due to the focus of the present study on a broad range of psychiatric symptoms rather than just on symptoms of PTSD. We did not shed light on the psychological impacts of the various negative events during the escaping period including personal trauma, family related problems and the asylum procedures themselves. Thus, the reason for this inconsistency needs further research in the future.

There was no significant relationship between education level in North Korea and psychiatric symptoms. These results are consistent with the findings of other studies, which suggest that education level was not a determining factor in the development of PTSD., ${ }^{2,43}$

The majority of defectors in South Korea have been receiving financial assistance or medical support from the government. ${ }^{1}$ In a previous study, their subjective satisfaction level with government support for medical care has been reported to be low. ${ }^{45}$ However, the use of mental health services by NKDs has not been reported. In our study, the majority of participants haven't used psychiatric services in spite of an apparent need of them, mainly because of lack of information.

One limitation of our study was its cross-sectional design, which made it impossible to identify causal relationships between psychiatric symptoms and other variables. And we also could not explore the changes in psychiatric symptoms through acculturation process.

In addition, this study did not use nationwide sample, so generalization of our results to all NKDs may be limited. However, this limitation is mitigated by the sample size, which is larger than those used in previous studies. ${ }^{2,42,46}$ Although far more females $(n=124)$ than males $(n=20)$ participated in the present research, in terms of statistical power the male sample 
Table 4. The mental health services utilization among North Korean defectors $(\mathrm{N}=144)$

\begin{tabular}{llc}
\hline & Variable & Frequency (\%) \\
\hline Needs for mental health service & Yes & $69(47.9)$ \\
& No & $75(52.1)$ \\
Mental health care Utilization & Yes & $24(16.7)$ \\
& No & $120(83.3)$ \\
Experienced service facilities & Mental health center & $1(4.2)$ \\
& Psychiatric ward (General hospital) & $17(70.8)$ \\
Reasons for poor access & Counseling or psychotherapy & $1(4.2)$ \\
& School (educational institution) & $2(8.3)$ \\
& The others & $3(12.5)$ \\
& Heavy cost & $6(8.5)$ \\
& Distance from their place of residence & $1(1.4)$ \\
& Insufficient information & $40(56.3)$ \\
\end{tabular}

size can be expected to be sufficiently large for gender effects to be detected in psychiatric symptoms. ${ }^{47}$

Thirdly, we did not use structured diagnostic interviews to assess psychiatric symptoms. However, the questionnaires we used have good reliability and validity, ${ }^{48-50}$ and are acceptable tools for use in the screening of the general population for psychiatric symptoms.

Lastly, there was no control group in the current study. Thus we could not assess if psychiatric symptoms would be more prevalent in North Korean defectors than control group.

In spite of several limitations, strengths of this study are that it is the first study into the relationship between physical illness and psychiatric symptoms among NKDs, and the utilization of mental health services by NKDs. The study is also unique in the use of the SCL-90-R for the assessment of psychiatric symptoms.

In conclusion, we found that somatization and depressive symptoms were the most prevalent psychiatric symptoms in NKDs. Psychiatric symptoms in NKDs were related to presence of physical illnesses, female gender, younger age, low economic status, and longer escaping period in a third country. These findings have several important implications for mental health policy makers for NKDs; the importance of intensification of physical health programs, employment programs and provision of sufficient information on mental health services. And we also suggest that an understanding of sociodemographic factors related to psychiatric symptoms will be helpful in providing appropriate mental health care to NKDs.

\section{Acknowledgments}

This research was financially supported by a grant from Gachon University Gil Hospital in 2010.

\section{REFERENCES}

1. Ministry of Unification, Republic of Korea. The Status of North Korean Defectors. Seoul: Ministry of Unification; 2009.

2. Jeon W, Hong C, Lee C, Kim DK, Han M, Min S. Correlation between traumatic events and posttraumatic stress disorder among North Korean defectors in South Korea. J Trauma Stress 2005;18:147-154.

3. Blair RG. Risk factors associated with PTSD and major depression among Cambodian refugees in Utah. Health Soc Work 2000;25:23-30.

4. Strober S. Social work interventions to alleviate Cambodian refugee psychological distress. Int Soc Work 1994;37:23-35.

5. Tyhurst L. Coping with refugees. A Canadian experience: 1948-1981. Int J Soc Psychiatry 1982;28:105-109.

6. Lin KM, Masuda M, Tazuma L. Adaptational problems of Vietnamese refugees. Part III. Case studies in clinic and field: adaptive and maladaptive. Psychiatr J Univ Ott 1982;7:173-183.

7. Westertmeyer J, Vang TF, Lyfong G. Hmong refugees in Minnesota. Characteristics and self perceptions. Minn Med 1983;66:431-439.

8. Gorst-Unsworth C, Goldenberg E. Psychological sequelae of torture and organised violence suffered by refugees from Iraq. Trauma-related factors compared with social factors in exile. Br J Psychiatry 1998; 172:90-94.

9. Laban CJ, Gernaat HB, Komproe IH, Schreuders BA, De Jong JT. Impact of a long asylum procedure on the prevalence of psychiatric disorders in Iraqi asylum seekers in the Netherlands. J Nerv Ment Dis 2004;192:843-851.

10. Lie B. A 3-year follow-up study of psychosocial functioning and general symptoms in settled refugees. Acta Psychiatr Scand 2002;106:415425.

11. Fazel M, Wheeler J, Danesh J. Prevalence of serious mental disorder in 7000 refugees resettled in Western countries: a systemic review. Lancet 2005;365:1309-1314.

12. Gerritsen AA, Bramsen I, Devillé W, van Willigen LH, Hovens JE, van der Ploeg HM. Health and health care utilisation among asylum seekers and refugees in the Netherlands: design of a study. BMC Public Health 2004;4:7.

13. Medecins Sans Frontieres South Korea Departments. The 2005 Annual Report- Mental Health for North Korean Refugee in South Korea; 2005.

14. Hong CH, Yoo JJ, Cho YA, Eom J, Ku HJ, Seo SW, et al. A 3-year followup study of posttraumatic stress disorder among North Korean defectors. J Korean Neuropsychiatr Assoc 2006;45:49-56. 
15. Hong CH, Jeon WT, Lee CH, Kim DK, Han M, Min SK. Relationship between traumatic events and posttraumatic stress disorder among North Korean refugees. J Korean Neuropsychiatr Assoc 2005;44:714-720.

16. Derogatis LR, Cleary PA. Factorial invariance across gender for the primary symptom dimensions of the SCL-90. Br J Soc Clin Psychol 1977;16:347-356.

17. Schmitz N, Kruse J, Tress W. Application of stratum-specific likelihood ratios in mental health screening. Soc Psychiatry Psychiatr Epidemiol 2000;35:375-379.

18. Jacobson NS, Truax P. Clinical significance: a statistical approach to defining meaningful change in psychotherapy research. J Consult Clin Psychol 1991;59:12-19.

19. Radloff LS. The CES-D scale: a self-report depression scale for research in the general population. Appl Psychol Meas 1977;1:385-401.

20. Cho MJ, Kim KH. Use of the Center for Epidemiologic Studies Depression (CES-D) Scale in Korea. J Nerv Ment Dis 1998;186:304-310.

21. Westermeyer J, Bouafuely M, Neider J, Callies A. Somatization among refugees: an epidemiologic study. Psychosomatics 1989;30:34-43.

22. Park SY, Bernstein KS. Depression and Korean American immigrants. Arch Psychiatr Nurs 2008;22:12-19.

23. Andreski P, Chilcoat H, Breslau N. Post-traumatic stress disorder and somatization symptoms: a prospective study. Psychiatry Res 1998;79: 131-138.

24. Escalona R, Achilles G, Waitzkin H, Yager J. PTSD and somatization in women treated at a VA primary care clinic. Psychosomatics 2004;45:291296.

25. Lin EH, Carter WB, Kleinman AM. An exploration of somatization among Asian refugees and immigrants in primary care. Am J Public Health $1985 ; 75: 1080-1084$.

26. Cho MJ, Nam JJ, Suh GH. Prevalence of symptoms of depression in a nationwide sample of Korean adults. Psychiatry Res 1998;81:341-352.

27. Jeon BH, Kim MD, Hong SC, Kim NR, Lee CI, Kwak YS, et al. Prevalence and correlates of depressive symptoms among North Korean defectors living in South Korea for more than one year. Psychiatry Investig 2009;6:122-130.

28. Han IY. Depressive traits of North Korean defectors. Ment Health Soc Work 2001;6:78-94.

29. Jeon WT. Survey results of adaptation and life of North Korean defectors in South Korea, 2001. Korean Unification Studies 2003;7:155-208.

30. Link B, Dohrenwend B. Formulation of Hypotheses about the True Prevalence of Demoralization in the United States. In: Dohrenwend BP, Dohrenwend BS, Gould MS, Link B, Neugebauer R and WunschHitzig R, Editors. Mental Illness in the United States: Epidemiological Estimates. New York: Praeger; 1980.

31. Frank J. Persuasion and Healing. New York: Schocken Books; 1973.

32. Koran LM, Sox HC Jr, Marton KI, Moltzen S, Sox CH, Kraemer HC, et al. Medical evaluation of psychiatric patients. I. Results in a state mental health system. Arch Gen Psychiatry 1989;46:733-740.

33. Kolody B, Vega W, Meinhardt K, Bensussen G. The correspondence of health complaints and depressive symptoms among Anglos and Mexican-Americans. J Nerv Ment Dis 1986;174:221-228.
34. Sandhu DS. Psychocultural profiles of Asian and Pacific Islander Americans: Implications for counseling and psychotherapy. J Multicult Couns Dev 1997;25:7-22.

35. Bhui K, Craig T, Mohamud S, Warfa N, Stansfeld SA, Thornicroft G, et al. Mental disorders among Somali refugees: developing culturally appropriate measures and assessing socio-cultural risk factors. Soc Psychiatry Psychiatr Epidemiol 2006;41:400-408.

36. Laban CJ, Gernaat HB, Komproe IH, van der Tweel I, De Jong JT. Postmigration living problems and common psychiatric disorders in Iraqi asylum seekers in the Netherlands. J Nerv Ment Dis 2005;193: 825-832.

37. Nwadiora E, McAdoo H. Acculturative stress among Amerasian refugees: gender and racial differences. Adolescence 1996;31:477-487.

38. Chung RC. Predictors of distress among Southeast Asian refugees group and gender differences. Paper presented at the Asian American Psychological Association Convention. San Francisco; 1991.

39. Hinton WL, Chen YC, Du N, Tran CG, Lu FG, Miranda J, et al. DSMIII-R disorders in Vietnamese refugees. Prevalence and correlates. J Nerv Ment Dis 1993;181:113-122.

40. Meinhardt K, Tom S, Tse P, Yu CY. Southeast Asian refugees in the "Silicon Valley": The Asian Health Assessment Project. Amerasia J 1986; 12:43-65.

41. Peters UH. The Stasi persecution syndrome. Fortschr Neurol Psychiatr 1991;59:251-265.

42. Yu SE, Jeon WT. Mental health of North Korean refugees in protective facilities in China. Psychiatry Investig 2008;5:70-77.

43. Jeon WT, Yoon DR, Min SK. An analysis of North Korean defector supporting experience of South Korean policemen in charge. J Korean Neuropsychiatr Assoc 2001;40:203-216.

44. Caspi Y, Poole C, Mollica RF, Frankel M. Relationship of child loss to psychiatric and functional impairment in resettled Cambodian refugees. J Nerv Ment Dis 1998;186:484-491.

45. Jeon WT, Yu SE, Eom JS. A seven-year panel study on North Korean defectors perception and satisfaction on life in South Korea. J Korean Neuropsychiatr Assoc 2010;49:90-103.

46. Jeon WT, Yu SE, Cho YA, Eom JS. Traumatic experiences and mental health of North Korean refugees in South Korea. Psychiatry Investig 2008;5:213-220.

47. Renner W, Salem I. Post-traumatic stress in asylum seekers and refugees from Chechnya, Afghanistan, and West Africa: gender differences in symptomatology and coping. Int J Soc Psychiatry 2009;55:99-108.

48. Al-Modallal H. Screening depressive symptoms in Jordanian women: evaluation of the Center for Epidemiologic Studies-Depression scale (CES-D). Issues Ment Health Nurs 2010;31:537-544.

49. Zauszniewski JA, Graham GC. Comparison of short scales to measure depressive symptoms in elders with diabetes. West J Nurs Res 2009;31: 219-234.

50. Spijker J, van der Wurff FB, Poort EC, Amits CH, Verhoeff AP, Beekman AT. Depression in first generation labor migrants in Western Europe: the utility of the Center for Epidemiologic Studies Depression Scale (CES-D). Int J Geriatr Psychiatry 2004;19:538-544. 